\title{
Stress-strain model for concrete confined by FRP composites
}

\author{
Marwan N. Youssef, Maria Q. Feng, Ayman S. Mosallam * \\ Department of Civil and Environmental Engineering, University of California, Irvine, CA 92697-2175, USA
}

Received 12 March 2006; accepted 16 July 2006

Available online 27 December 2006

\begin{abstract}
In this paper, a stress-strain model for concrete confined by fiber reinforced polymer (FRP) composites is developed. The model is based on the results of a comprehensive experimental program including large-scale circular, square and rectangular short columns confined by carbon/epoxy and E-glass/epoxy jackets providing a wide range of confinement ratios. Ultimate stress, rupture strain, jacket parameters, and cross-sectional geometry were found to be significant factors affecting the stress-strain behavior of FRP-confined concrete. Such parameters were analyzed statistically based on the experimental data, and equations to theoretically predict these parameters are presented. Experimental results from this study were compared to the proposed semi-empirical model as well as others from the literature.
\end{abstract}

(C) 2007 Elsevier Ltd. All rights reserved.

Keywords: A. Laminates; A. Polymer-matrix composites (PMCs); C. Analytical modeling; D. Mechanical testing; Concrete

\section{Introduction}

The need for strengthening deficient existing reinforced concrete $(\mathrm{RC})$ columns is triggered by many reasons. For years, engineers have been studying ways to retrofit or strengthen existing deficient RC columns to meet new code requirements, especially in earthquake prone areas. The use of fiber reinforced polymers (FRP) jackets as an external mean to strengthen existing $\mathrm{RC}$ columns has emerged in recent years with very promising results $[1,3,4,7,8]$. Especially for circular columns, such technique has proved to be very effective in enhancing their ductility and axial load capacity $[2,12,25]$. Recently many studies have been conducted to evaluate the ultimate strength and strain enhancement of FRP-confined concrete $[14,15,21,22,26,28,31-33]$. This field; however, remains in its infancy stages and more studies are needed to explore its capabilities, limitations, and design applicability. Many researchers and design engineers are still using steel-confined concrete models in predicting the behavior and

\footnotetext{
${ }^{*}$ Corresponding author.

E-mail address: mosallam@uci.edu (A.S. Mosallam).
}

design of FRP strengthened columns [19]. This is caused by the fact that a general FRP-confined concrete model is yet to be adopted by industry codes. As expected, studies have shown that FRP-confined concrete behaves differently from steel-confined concrete [20]. As a result, several FRP-confinement models have been developed to fill the gap and to better understand the behavior of the FRP jackets $[9,11,16,27,29]$. The majority, if not all, of such models have been developed from experimental data produced by testing small concrete specimens wrapped with FRP jackets. The most popular specimen size used is the conventional $152 \mathrm{~mm} \times 305 \mathrm{~mm}$ ( 6 in. $\times 12$ in.) standard concrete cylinders, and some researchers even used $76 \mathrm{~mm} \times 305 \mathrm{~mm}$ ( 3 in. $\times 12$ in.) [30]. Consequently models were developed based on limited test database, and therefore, its applicability is unclear, especially with regard to a wide range of confinement ratios.

This paper presents a new general confinement model developed by the authors for FRP-confined concrete, based on testing large-scale axially loaded specimens with a wide range of confinement ratios [36,37]. This model is applicable to circular as well as rectangular concrete columns retrofitted by FRP jackets. The model predicts the ultimate 


\begin{tabular}{|c|c|}
\hline \multicolumn{2}{|c|}{ Nomenclature } \\
\hline$A_{\mathrm{c}}$ & cross-sectional area of concrete \\
\hline$A_{\mathrm{j}}$ & cross-sectional area of FRP jacket \\
\hline$A_{\mathrm{s}}$ & total area of longitudinal steel in a column \\
\hline$b$ & width of rectangular section \\
\hline$D$ & diameter of circular column \\
\hline$E_{\mathrm{c}}$ & modulus of elasticity of concrete \\
\hline$E_{\mathrm{j}}$ & $\begin{array}{l}\text { tensile modulus of FRP jacket in the hoop direc- } \\
\text { tion }\end{array}$ \\
\hline$f_{\mathrm{c}}^{\prime}$ & $\begin{array}{l}\text { compressive strength of unconfined concrete } \\
\text { (measured on the day of test) }\end{array}$ \\
\hline$f_{\mathrm{cu}}^{\prime}$ & ultimate strength of FRP-confined concrete \\
\hline$f_{1}$ & lateral confining stress \\
\hline$f_{\mathrm{c}}$ & concrete stress \\
\hline$f_{\mathrm{jt}}$ & $\begin{array}{l}\text { FRP jacket stress at transition from first to sec- } \\
\text { ond region }\end{array}$ \\
\hline$f_{\mathrm{ju}}$ & tensile strength of FRP jacket \\
\hline$f_{\mathrm{lu}}$ & $\begin{array}{l}\text { lateral confining stress at ultimate condition of } \\
\text { FRP jacket }\end{array}$ \\
\hline$f_{\text {lu }}^{\prime}$ & $\begin{array}{l}\text { effective lateral confining stress at ultimate con- } \\
\text { dition of FRP jacket }\end{array}$ \\
\hline
\end{tabular}

\section{Nomenclature}

$A_{\mathrm{c}} \quad$ cross-sectional area of concrete

$A_{\mathrm{j}} \quad$ cross-sectional area of FRP jacket

$A_{\mathrm{s}} \quad$ total area of longitudinal steel in a column

$b$

$D$

$E_{\mathrm{c}}$

$E_{\mathrm{j}}$

$f_{c}$

$f_{\mathrm{c}}^{\prime}$

$f_{\mathrm{c}}$

$f_{\mathrm{jt}}$

$f_{\mathrm{ju}}$

$f_{\mathrm{lu}}^{\prime}$ $f_{\mathrm{t}}$

depth of rectangular section

$k_{\mathrm{e}} \quad$ confinement effectiveness coefficient

$r_{\mathrm{c}} \quad$ corner radius of rectangular section

$t_{\mathrm{j}} \quad$ total thickness of FRP jacket

$t_{1} \quad$ thickness per layer of FRP jacket

$\varepsilon_{\mathrm{c}} \quad$ strain in concrete

$\varepsilon_{\mathrm{cu}} \quad$ ultimate confined concrete compressive strain

$\varepsilon_{\mathrm{jt}} \quad$ FRP jacket strain at transition from first to second region $=0.002$ ultimate tensile strain of FRP jacket

$\varepsilon_{\mathrm{ju}}$

$\varepsilon_{\mathrm{t}}$ axial strain at the boundary point of the first and second region where the jacket is beginning to get fully activated

$\rho_{\mathrm{j}} \quad$ volumetric ratio of FRP jacket

$\rho_{1} \quad$ area ratio of longitudinal reinforcement strength, ultimate stain, and depicts the entire stress-strain diagram for FRP-confined concrete specimens.

\section{Experimental program}

\subsection{Test specimen}

A total of 87 large unreinforced specimens were tested under pure axial load. In addition a total of $30-152 \mathrm{~mm} \times$ $305 \mathrm{~mm}$ (6 in. $\times 12$ in.) concrete cylinders were tested. Table 1 shows the test program conducted in this study.

Both carbon/epoxy and E-glass/epoxy jackets were used to confine the column specimens. Table 2 presents the complete material properties used in the study. The FRP laminates were applied directly to the pretreated surfaces of the specimens providing unidirectional lateral confinement in the hoop direction. An overlap of $152 \mathrm{~mm}$ (6-in.) was used to ensure the development of full composite tensile strength. Ready-mix concrete with nominal 28-day strength of $27.58 \mathrm{MPa}$ (4000 psi) to $34.47 \mathrm{MPa}$ (5000 psi) was used.

All specimens were instrumented with strain gages bonded to both the concrete surfaces and external laminates, at two perpendicular directions. The strain gages were placed at mid-height of the specimen. Two linear variable differential transducers (LVDT) per specimen were used, 180 degrees apart, to capture the vertical displacements over the middle half of the specimens. For the $152 \mathrm{~mm} \times 305 \mathrm{~mm}$ ( 6 in. $\times 12$ in.) cylinders, both ends of all cylinders were capped using sulfur capping to insure parallel surfaces and to distribute the load uniformly in order to reduce load eccentricity.

\subsection{Testing machine}

The 31,000 kN (7-million pound) compression machine used to crush the specimens is a 4-post up-acting hydraulic press. The bottom cylinder is designed to swivel in order to minimize eccentricity. This $4.88 \mathrm{~m}$ (16 ft) high machine, shown in Fig. 1, is very unique in terms of its very large loading capacity; $173 \mathrm{~cm}$ (68 in.) open daylight; $94 \mathrm{~cm}$ (37 in.) diameter main cylinder, and an over all weight of $50,000 \mathrm{~kg}(110,000 \mathrm{lbs})$ [34-36].

\section{Mechanics of confinement}

Under low level of longitudinal strain, the concrete is known to behave elastically and the transverse strain is related proportionally to the longitudinal strain by the Poisson's ratio. As the load increases, cracks start to form leading to a large increase in the transverse strain.

Assuming deformation compatibility, the lateral strain of the confined specimens is equal to the strain in the FRP jacket. The tendency of concrete to dilate after cracking and the radial stiffness of the confining jacket to restrain the concrete dilation, are considered to be two important factors affecting the concrete confinement.

By wrapping the concrete with an external continuous FRP jacket, the fibers in the hoop direction resist the transverse expansion of the concrete providing a confining pressure. At low levels of longitudinal stress; however, the transverse strains are so low that the FRP jacket induces little confinement, if any. At higher longitudinal stress levels, the dramatic increase in transverse tensile strains activates the FRP jacket and the confining pressure becomes 


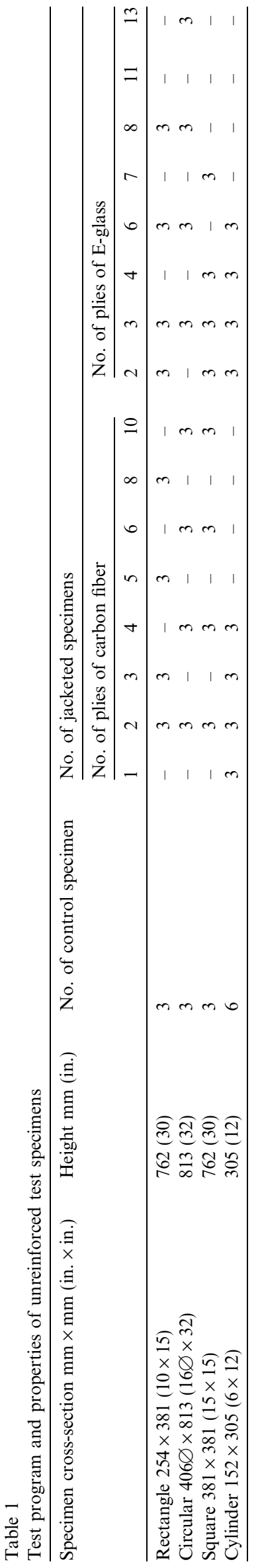

more significant. The general confining pressure induces a tri-axial state of stress in the concrete. It is well understood that concrete under tri-axial compressive stress exhibits superior behavior, in both strength and ductility, as compared to concrete in uniaxial compression [24].

\subsection{Lateral confining stress, $f_{\mathrm{lu}}$}

The lateral confining stress $\left(f_{\text {lu }}\right)$ is produced in confined concrete when the member is loaded such that the concrete starts to dilate and expands laterally. The value of such stress depends on the cross-section geometry of the confined member and the amount and mechanical properties of confining materials provided. For example, when confining a circular member, the FRP jacket provides a uniform confining stress around the parameter resulting in a great improvement in member's behavior under loading. On the other hand, confining square or rectangular members tends to produce confining stress concentrated around the corners of such members, as shown in Fig. 2. In fact, all of the square and rectangular columns tested in this study failed by the rupture of the FRP jacket that started at one of the corners.

\subsection{Effective lateral confining stress $f_{\mathrm{lu}}^{\prime}$}

To study and quantify the behavior of concrete members confined by FRP jacket, the amount of confining pressure (stress) provided by the jacket should be determined. Such confining pressure is a function of the column's cross-section, the stiffness of the FRP jacket, and the transverse expansion of the loaded concrete. To calculate the lateral confining stress, $f_{\text {lu }}$, applied to the concrete by confinement, a free-body diagram of a circular crosssection confined with an FRP jacket is considered as shown in Fig. 3.

Based on static analysis, equilibrium of forces, deformation compatibility, and by considering $1 \mathrm{ft}(0.30 \mathrm{~m})$ section along the column height, the following expression can be written:

$f_{\mathrm{lu}}=\frac{2 f_{\mathrm{ju}} t_{\mathrm{j}}}{D}$

Introducing $\rho_{\mathrm{j}}$ as the confinement ratio, which is defined as the jacket volume divided by the concrete volume, i.e.,

$\rho_{\mathrm{j}}=\frac{4 t_{\mathrm{j}}}{D}$

Substitute in Eq. (1), we have

$f_{\mathrm{lu}}=\frac{1}{2} \rho_{\mathrm{j}} f_{\mathrm{ju}}$

The effective lateral confining stress at ultimate condition of the FRP jacket is defined as

$f_{\mathrm{lu}}^{\prime}=k_{\mathrm{e}} f_{\mathrm{lu}}$ 
Table 2

Mechanical properties of the composite systems

\begin{tabular}{lllll}
\hline System & Thickness per layer mm (in.) & Young's modulus $E_{\mathrm{j}} \mathrm{GPa}(\mathrm{Msi})$ & Tensile strength $f_{\mathrm{ju}}$ MPa $(\mathrm{ksi})$ & Failure strain $\varepsilon_{\mathrm{ju}}(\%)$ \\
\hline Carbon/epoxy & $0.584(0.023)$ & $103.8(15.06)$ & $1246(180.7)$ & 1.25 \\
E-glass/epoxy & $0.559(0.022)$ & $18.5(2.68)$ & $425(61.6)$ & 2.16 \\
E-glass/epoxy & $1.143(0.045)$ & $18.5(2.68)$ & $425(61.6)$ & 2.16 \\
\hline
\end{tabular}

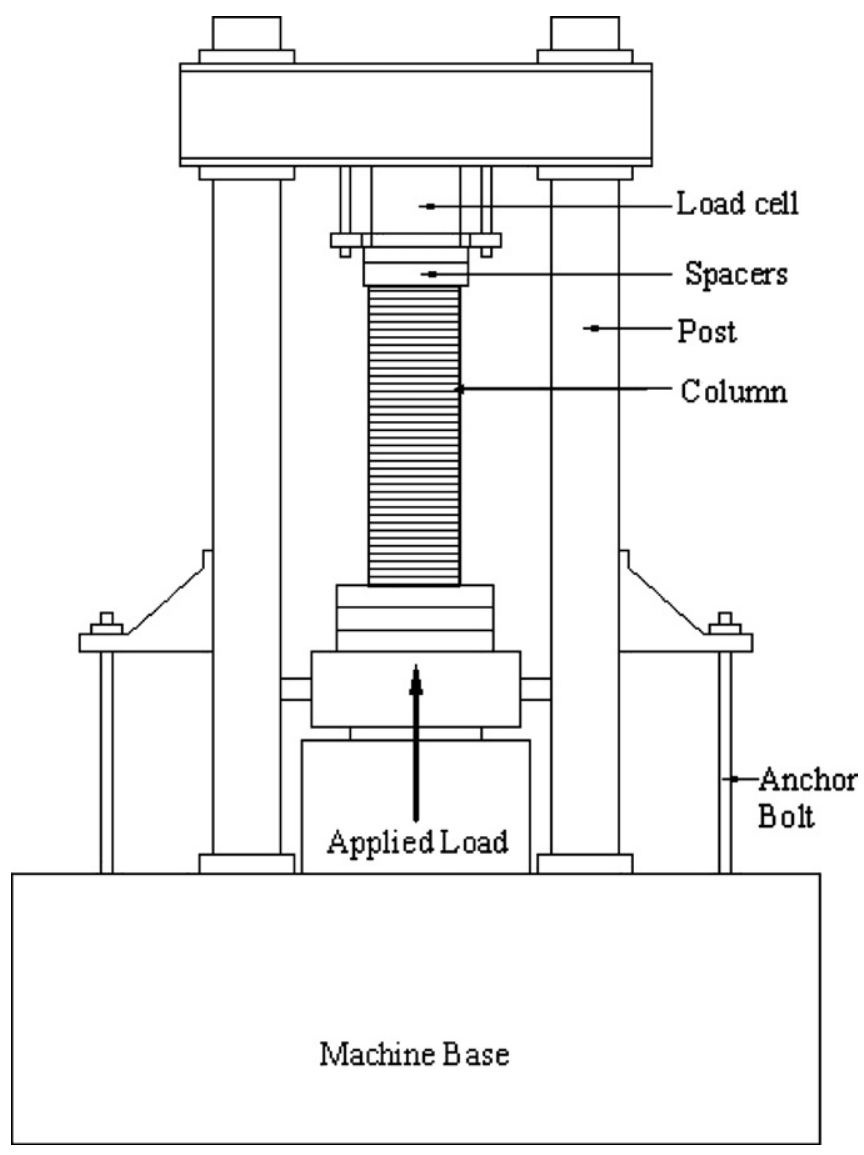

Fig. 1. Setup for testing large concrete columns.

where $k_{\mathrm{e}}$ is the confinement effectiveness coefficient. For circular columns, $k_{\mathrm{e}}=1.0$.

Similarly, for rectangular sections, it can be shown that $f_{\mathrm{lu}}=\frac{1}{2} \rho_{\mathrm{j}} f_{\mathrm{ju}}$

Unlike the circular section, however, the confinement effectiveness coefficient for rectangular section is less than unity (i.e. $k_{\mathrm{e}}$ is less than one). The values of $k_{\mathrm{e}}$ are calculated using the expression proposed by Restrepo and DeVino [23]. For rectangular and square columns,

$k_{\mathrm{e}}=\frac{1-\left[\frac{\left(b-2 r_{\mathrm{c}}\right)^{2}+\left(h-2 r_{\mathrm{c}}\right)^{2}}{3 h b}\right]-\rho_{1}}{1-\rho_{1}}$

where $b$ and $h$ are the width and depth of the cross-section, respectively; $r_{\mathrm{c}}$ is the corner radius of the column; $\rho_{1}$ is the longitudinal reinforcement ratio of the section $=\frac{A_{\mathrm{s}}}{b h}$, where $A_{\mathrm{s}}$ is the area of the longitudinal steel.

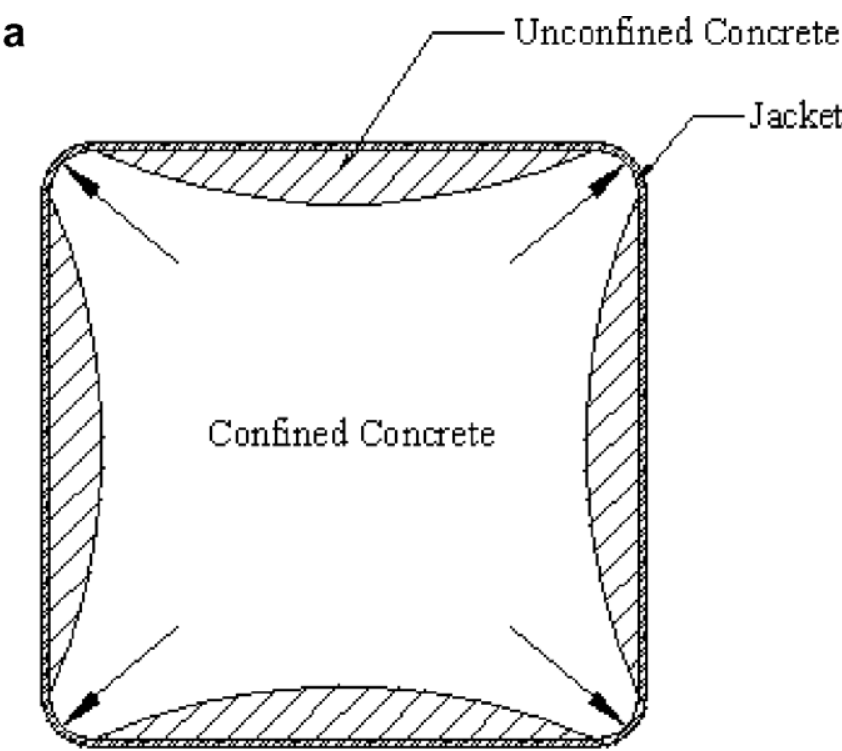

b

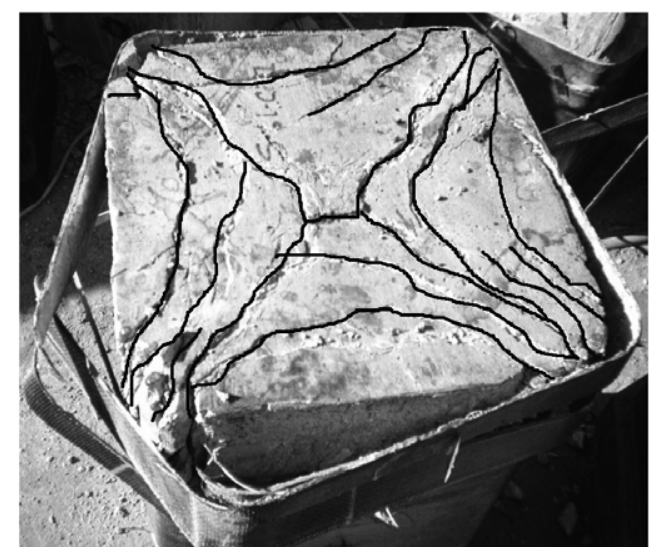

Fig. 2. Confinement of concrete columns with FRP composite jackets. (a) Confined and unconfined portions of square section. (b) Dilated square column confined with carbon/epoxy jacket.

\subsection{Development of general FRP confinement model}

In order to develop a theoretical stress-strain model for concrete confined by FRP jacket, the experimental results in the form of axial stress versus axial strain must be produced and analyzed carefully. As expected, the stress-strain diagram of the tested specimen indicates three different stages are encountered throughout the testing scheme. The three stages are:

Stage 1: During this stage, the initial portion of the stressstrain response of confined concrete follows the path of unconfined concrete. Therefore, the slope 


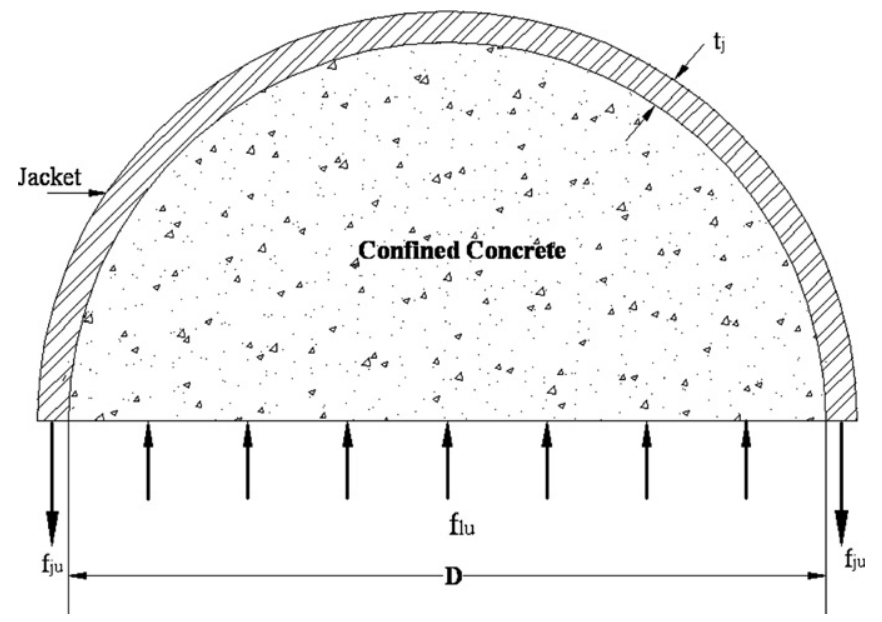

Fig. 3. Free body diagram of circular column confined by FRP jacket.

of the curve in this stage is taken as, $E_{\mathrm{c}}$, the concrete modulus of elasticity. Other researchers used different formulas to calculate $E_{\mathrm{c}}$; however, in this study, the experimental results correlated very well with the value for $E_{\mathrm{c}}$ recommended by ACI 318 , where

$E_{\mathrm{c}}=4700 \sqrt{f_{\mathrm{c}}^{\prime}} \quad(\mathrm{MPa})$

$E_{\mathrm{c}}=57,000 \sqrt{f_{\mathrm{c}}^{\prime}} \quad(\mathrm{psi})$

The proposed model was, therefore, developed based on this value of $E_{\mathrm{c}}$.

Stage 2: After exceeding the unconfined strength of concrete, the stress-strain curve starts to soften forming a transition zone within which cracks in the concrete starts to expand and the concrete start to dilate and bear against the jacket activating it.

Stage 3: The FRP jacket at this stage is fully activated and the confining stress provided by the jacket continues to increase proportional to the applied load until failure. Within this stage, the experimental results indicate that the curve exhibits a linear behavior up to the rupture of the jacket. This fact was also reported by other researchers $[6,27,26]$. This portion of the curve; however, was observed to be either ascending or descending, depending of the cross-sectional geometry of the column and the amount of FRP confinement provided.

Based on these observations, the general stress-strain curve shown in Fig. 4 will be used in the modeling process for FRP-confined concrete.

The ascending curve would represent situations where the slope of the curve, $E_{2}$, in the third zone is positive. This would be the case of columns with moderate to high confinement ratios which also depends on the geometry of the cross-section. Circular columns, for instance, with moderate confinement ratio usually have an ascending stress-strain curve.

The descending curve represents low confinement for circular cross-sections and low to moderate confinement for rectangular sections. The fact that the intent is to develop a general confinement model for FRP-confined concrete, both ascending and descending cases are carefully addressed in this study. The essential points along the stress-strain curve of interest are:

Point A: The beginning point before the load is applied where the axial stress and axial strain are zero.

Point B: Represents the end of stage 2 where the jacket is getting fully activated under the effect of tensile stresses due to concrete dilation. From this point on, the stress provided by the jacket will continue to increase until jacket rupture. This point will be represented by $\varepsilon_{\mathrm{t}}$ and $f_{\mathrm{t}}$ as $x$ and $y$ coordinates, respectively.

Point C: Point $\mathrm{C}$ represents the ultimate condition where the jacket fails at an ultimate axial stress $f_{\mathrm{cu}}^{\prime}$, and an ultimate axial strain of $\varepsilon_{\mathrm{cu}}$. The term $f_{\mathrm{cu}}^{\prime}$

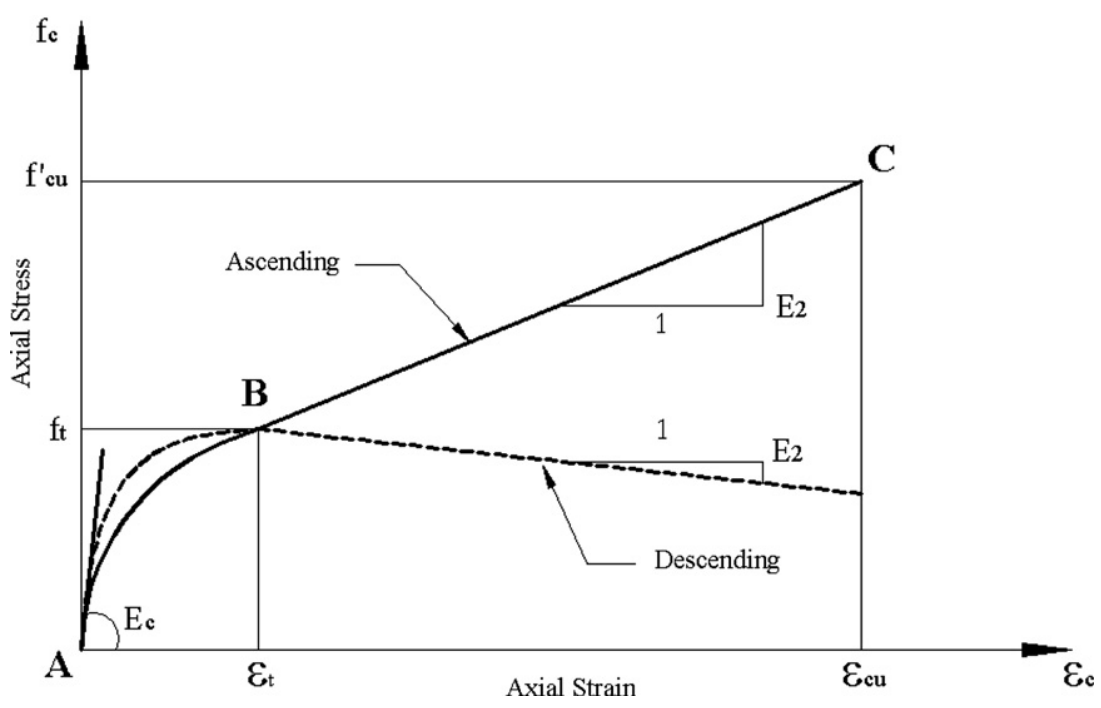

Fig. 4. Proposed model for FRP-confined concrete. 
will be defined as the ultimate strength of FRPconfined concrete, and $\varepsilon_{\mathrm{cu}}$ as the ultimate confined concrete compressive strain.

In the analysis, the stress-strain curve is divided into two regions, $0 \leqslant \varepsilon_{\mathrm{c}} \leqslant \varepsilon_{\mathrm{t}}$, and $\varepsilon_{\mathrm{t}} \leqslant \varepsilon_{\mathrm{c}} \leqslant \varepsilon_{\mathrm{cu}}$. In the first region, the experimental data, for both circular and rectangular columns, trace that of unconfined concrete path. In the second region; however, the curve for circular sections with moderate confinement level was linear with a positive (ascending) slope. The second portion of the curve, in most cases of rectangular and square columns, maintained a negative (descending) slope for most of the confinement ratios used. Even circular columns with low confinement ratio exhibit a descending behavior. In order to develop a unified model, both cases, $E_{2}>0$, and $E_{2}<0$ are considered.

In order to describe the analytical proposed curve, several parameters were defined and established. The most important parameters are the ultimate strength of FRPconfined concrete, $f_{\mathrm{cu}}^{\prime}$, and the ultimate confined concrete compressive strain, $\varepsilon_{\mathrm{cu}}$. Other parameters needed are $f_{\mathrm{t}}$ and $\varepsilon_{t}$, which are the axial stress and axial strain at the transition boundary point at the end of stage 2 and the beginning of stage 3 , respectively.

Using a similar approach used by Hoshikuma et al. [10] to develop a confinement model for concrete confined by transverse steel, it is proposed that the concrete stress in region $1\left(0 \leqslant \varepsilon_{\mathrm{c}} \leqslant \varepsilon_{\mathrm{t}}\right)$ be modeled by the following polynomial function:

$f_{\mathrm{c}}=C_{1} \varepsilon_{\mathrm{c}}^{n}+C_{2} \varepsilon_{\mathrm{c}}+C_{3}$

where $C_{1}, C_{2}, C_{3}$, and $n$ are constants to be determined from the following boundary conditions.

First region where $0 \leqslant \varepsilon_{\mathrm{c}} \leqslant \varepsilon_{\mathrm{t}}$, and $E_{2}>0$,

(1) $f_{\mathrm{c}}=0 @ \varepsilon_{\mathrm{c}}=0$,

(2) $\mathrm{d} f_{\mathrm{c}} / \mathrm{d} \varepsilon_{\mathrm{c}}=E_{\mathrm{c}} @ \varepsilon_{\mathrm{c}}=0$,

(3) $\mathrm{d} f_{\mathrm{c}} / \mathrm{d} \varepsilon_{\mathrm{c}}=E_{2} @ \varepsilon_{\mathrm{c}}=\varepsilon_{\mathrm{t}}$,

(4) $f_{\mathrm{c}}=f_{\mathrm{t}} @ \varepsilon_{\mathrm{c}}=\varepsilon_{\mathrm{t}}$.

Now, substituting the four boundary conditions in Eq. (9) one obtains

$f_{\mathrm{c}}=E_{\mathrm{c}} \varepsilon_{\mathrm{c}}\left[1-\frac{1}{n}\left(1-\frac{E_{2}}{E_{\mathrm{c}}}\right)\left(\frac{\varepsilon_{\mathrm{c}}}{\varepsilon_{\mathrm{t}}}\right)^{n-1}\right]$

$n=\frac{\left(E_{\mathrm{c}}-E_{2}\right) \varepsilon_{\mathrm{t}}}{E_{\mathrm{c}} \varepsilon_{\mathrm{t}}-f_{\mathrm{t}}}$

First region where $0 \leqslant \varepsilon_{\mathrm{c}} \leqslant \varepsilon_{\mathrm{t}}$, and $E_{2}<0$,

When $E_{2}<0$, the third boundary condition above is changed to reflect the fact that, from experimental observation, a tangent to the curve at $\left(\varepsilon_{\mathrm{t}}, f_{\mathrm{t}}\right)$ is a horizontal straight line.

$\mathrm{d} f_{\mathrm{c}} / \mathrm{d} \varepsilon_{\mathrm{c}}=0 @ \varepsilon_{\mathrm{c}}=\varepsilon_{\mathrm{t}}$

Substituting the four boundary conditions, with the revised third condition (Eq. (12)) into Eq. (9), one obtains

$$
\begin{aligned}
& f_{\mathrm{c}}=E_{\mathrm{c}} \varepsilon_{\mathrm{c}}\left[1-\frac{1}{n}\left(\frac{\varepsilon_{\mathrm{c}}}{\varepsilon_{\mathrm{t}}}\right)^{n-1}\right] \\
& n=\frac{E_{\mathrm{c}} \varepsilon_{\mathrm{t}}}{E_{\mathrm{c}} \varepsilon_{\mathrm{t}}-f_{\mathrm{t}}}
\end{aligned}
$$

Second region where $\varepsilon_{\mathrm{t}} \leqslant \varepsilon_{\mathrm{c}} \leqslant \varepsilon_{\mathrm{cu}}$.

Applicable to both ascending and descending cases, the stress-strain diagram is modeled as a straight line between two points described as

$f_{\mathrm{c}}=a \varepsilon_{\mathrm{c}}+b$

where $a$ and $b$ are constants determined from the following boundary conditions:

(1) $f_{\mathrm{c}}=f_{\mathrm{t}} @ \varepsilon_{\mathrm{c}}=\varepsilon_{\mathrm{t}}$,

(2) $f_{\mathrm{c}}=f_{\mathrm{cu}}^{\prime} @ \varepsilon_{\mathrm{c}}=\varepsilon_{\mathrm{cu}}$.

Substituting the two boundary conditions in Eq. (15), one obtains

$f_{\mathrm{c}}=f_{\mathrm{t}}+E_{2}\left(\varepsilon_{\mathrm{c}}-\varepsilon_{\mathrm{t}}\right)$

\subsection{Evaluation of model parameters}

In the proposed model, the following control parameters are of interest: (i) the ultimate strength of FRP-confined concrete, $f_{\text {cu }}^{\prime}$; (ii) the ultimate concrete compressive strain, $\varepsilon_{\mathrm{cu}}$; (iii) the axial stress at the boundary point between the first and second region, $f_{\mathrm{t}}$; (iv) the axial strain that corresponding to $f_{\mathrm{t}}, \varepsilon_{\mathrm{t}} ;(\mathrm{v})$ and slope of the stress-strain curve within the second region, $E_{2}$.

The effect of confinement provided by the external jacket is determined using regression analysis of the experimental data produced from this study, as well as data from other researchers $[5,11,13]$. Although the literature contains many experimental data on the subject of FRPconfined concrete, the majority of the data is obtained from standard $152 \mathrm{~mm} \times 305 \mathrm{~mm}$ ( 6 in. $\times 12$ in.) cylinders tests. In this modeling task, large and small specimens are considered to cover a larger range of sizes and confinement ratios.

The main parameters that are likely to influence the confinement effect produced by an external FRP jacket are the following: (i) volumetric ratio of FRP jacket, $\rho_{j}$; (ii) tensile strength of FRP jacket, $f_{\mathrm{ju}}$; (iii) tensile modulus of elasticity of FRP jacket in the hoop direction, $E_{\mathrm{j}}$; (iv) ultimate tensile strain of FRP jacket, $\varepsilon_{\text {ju }}$; (v) compressive strength of unconfined concrete, $f_{\mathrm{c}}^{\prime}$; (vi) cross-section of the concrete specimen and its dimensions.

\subsubsection{Ultimate strength of FRP-confined concrete, $f_{\mathrm{cu}}^{\prime}$}

This parameter is one of the two most important parameters of a stress-strain model for confined concrete. The ultimate strength is the stress reached by the confined concrete just before failure. For retrofitted circular columns, the ultimate stress, for moderate to high confinement ratios, is always higher than the unconfined concrete 
stress, and the stress-strain curve is almost always ascending. The increase in the ultimate stress is due to the uniform confinement around a circular cross-section provided by the external jacket. For square and rectangular specimens, on the other hand, the stress-strain curve is mostly descending except in cases where the confinement ratio is very high. Even then, the curve is only slightly ascending. All of these statements were observed in the experimental phase of this study, and were considered in the model development.

A formula relating the ultimate strength of FRP-confined concrete to parameters that would impact its value is usually referred to as a "Strength Model". Such formula usually represents a linear relationship between the confinement effectiveness factor, $\frac{f_{\mathrm{cu}}^{\prime}}{f_{\mathrm{c}}^{\prime}}$, and the confinement ratio, $\frac{f_{1}}{f_{\mathrm{c}}^{\prime}}$, as follows:

$\frac{f_{\mathrm{cu}}^{\prime}}{f_{\mathrm{c}}^{\prime}}=1+k_{1} \frac{f_{1}}{f_{\mathrm{c}}^{\prime}}$

where $k_{1}$ is the effectiveness coefficient described earlier. Using regression analysis, the confinement effectiveness factor, $\frac{f_{\mathrm{fu}}^{\prime}}{f_{\mathrm{c}}^{\prime}}$, and the confinement ratio, $\frac{f_{\mathrm{lu}}^{\prime}}{f_{\mathrm{c}}^{\prime}}$, were related for circular and rectangular specimens using linear relationship as shown in Figs. 5 and 6.

The following strength model is proposed, depending on the geometry of the cross-section:

$\frac{f_{\mathrm{cu}}^{\prime}}{f_{\mathrm{c}}^{\prime}}=\left\{\begin{array}{l}\text { For circular sections } \\ 1.0+2.25\left(\frac{f_{\mathrm{lu}}^{\prime}}{f_{\mathrm{c}}^{\prime}}\right)^{\frac{5}{4}} \\ \text { For rectangular sections } \\ 0.5+1.225\left(\frac{f_{\mathrm{lu}}^{\prime}}{f_{\mathrm{c}}^{\prime}}\right)^{\frac{3}{5}}\end{array}\right.$

The correlation coefficient for the circular sections is $93 \%$, using 63 data points, and that for the rectangular sections is $94 \%$ using 38 data points.

\subsubsection{Ultimate concrete compressive strain, $\varepsilon_{\mathrm{cu}}$}

The ultimate concrete compressive strain is considered also to be a very important parameter of the stress-strain curve of confined concrete. In order to calculate the available ultimate rotation capacity at a plastic hinge in a reinforced concrete flexural member, it is necessary to be able to predict the ultimate concrete compressive strain $\varepsilon_{\mathrm{cu}}$.

Similar to strength models, the formula for determining the ultimate concrete compressive strain is some time referred to as a "Strain Model". The effective confining stress, $f_{\text {lu }}^{\prime}$, a function of specimen's cross-section and jacket characteristics, as well as the mechanical properties of the jacket, will be used in the regression analysis to determine $\varepsilon_{\text {cu. }}$. Figs. 7 and 8 show the confinement effectiveness factor $\left(\frac{f_{\mathrm{fu}}^{\prime}}{f_{\mathrm{c}}^{\prime}}\right)\left(\frac{f_{\mathrm{ju}}}{E_{\mathrm{j}}}\right)^{\frac{1}{2}}$ versus the ultimate compressive strain, $\varepsilon_{\mathrm{cu}}$. The relationship between $\varepsilon_{\mathrm{cu}}$ and $\left(\frac{f_{\mathrm{ul}}^{\prime}}{f_{\mathrm{c}}^{\prime}}\right)\left(\frac{f_{\mathrm{ju}}}{E_{\mathrm{j}}}\right)^{\frac{1}{2}}$ may be approximated by a linear function. The following relationships are obtained from regression analysis:

$$
\varepsilon_{\mathrm{cu}}=\left\{\begin{array}{l}
\text { For circular sections } \\
0.003368+0.2590\left(\frac{f_{\mathrm{lu}}^{\prime}}{f_{\mathrm{c}}^{\prime}}\right)\left(\frac{f_{\mathrm{ju}}}{E_{\mathrm{j}}}\right)^{\frac{1}{2}} \\
\text { For rectangular sections } \\
0.004325+0.2625\left(\frac{f_{\mathrm{lu}}^{\prime}}{f_{\mathrm{c}}^{\prime}}\right)\left(\frac{f_{\mathrm{ju}}}{f_{\mathrm{c}}^{\prime}}\right)^{\frac{1}{2}}
\end{array}\right.
$$

The correlation coefficient for the circular sections is $94 \%$, using 63 data points, and that for the rectangular sections is $96 \%$ using 38 data points.

\subsubsection{Axial stress, $f_{\mathrm{t}}$}

Another parameter needed for predicting the entire stress-strain diagram is the axial stress at the boundary point between the first and second regions, $f_{\mathrm{t}}$. Although $f_{\mathrm{cu}}^{\prime}$ and $\varepsilon_{\mathrm{cu}}$ are considered to be the most important parameters of confined concrete, the ability to predict the entire

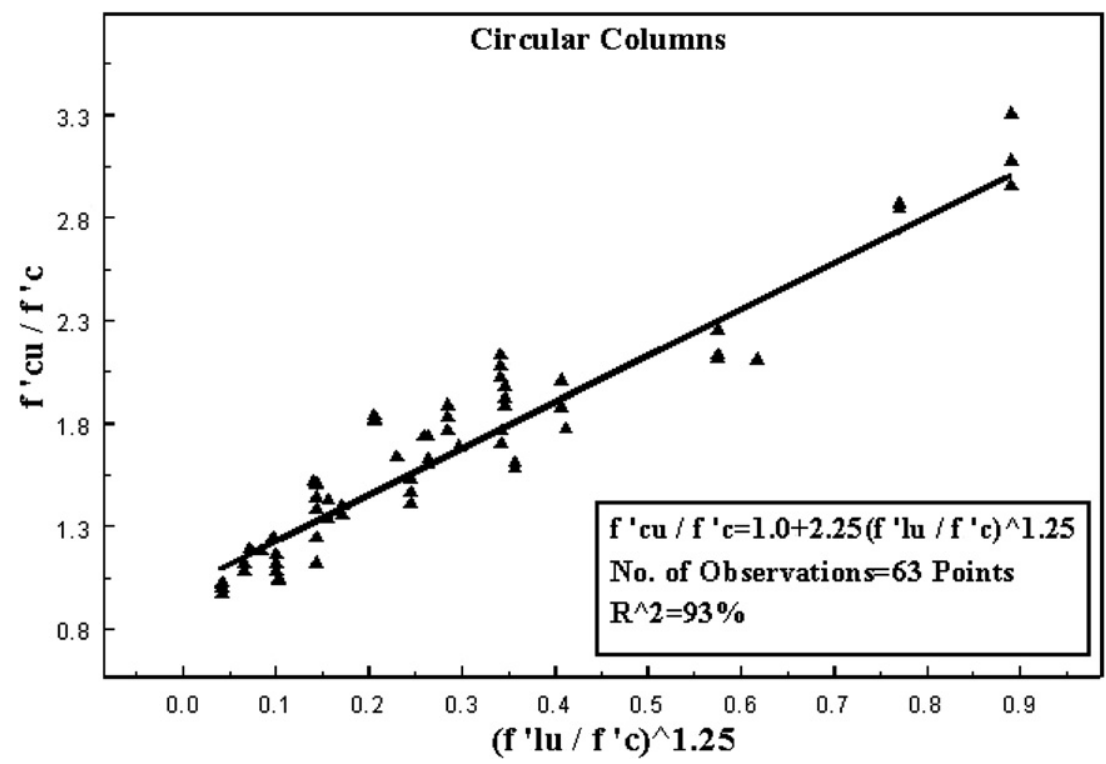

Fig. 5. Relation between confinement effectiveness and ultimate stress for circular columns. 


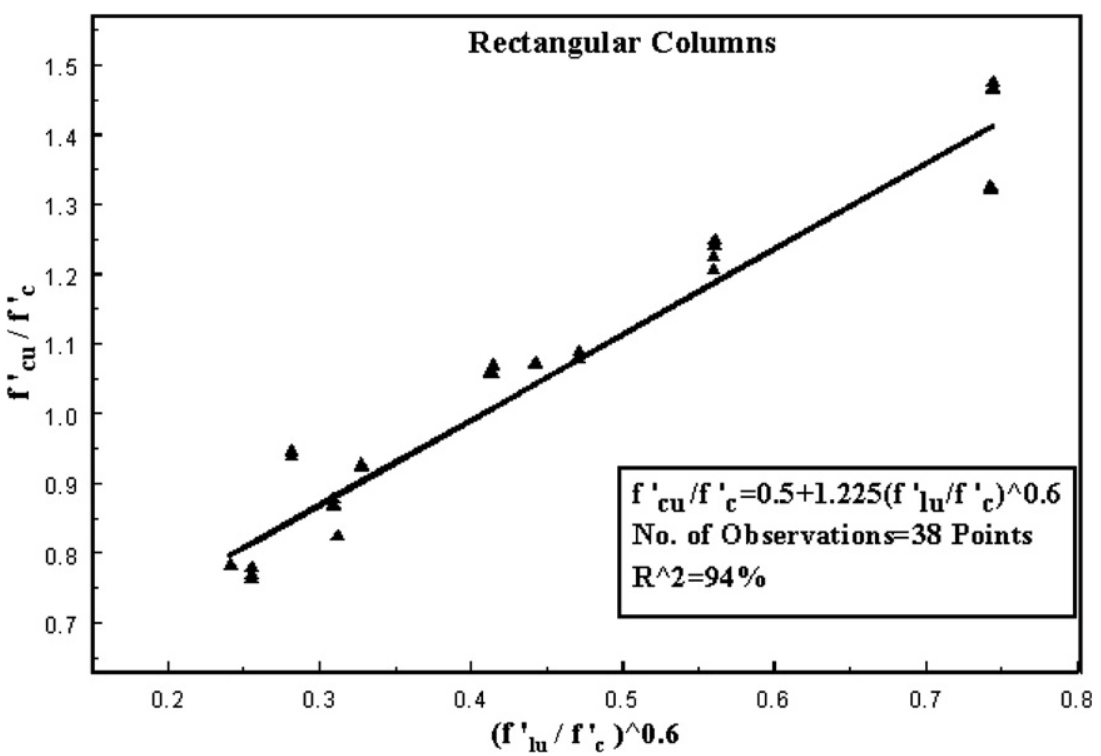

Fig. 6. Relation between confinement effectiveness and ultimate stress for rectangular columns.

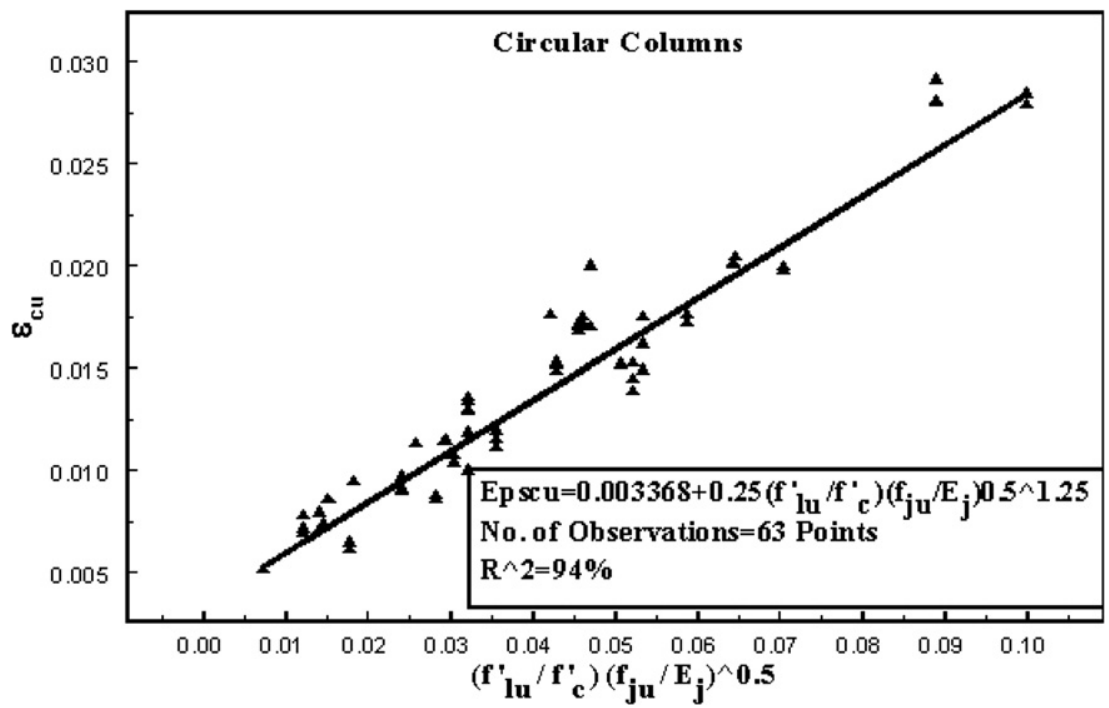

Fig. 7. Relationship for the ultimate strain for circular columns.

stress-strain curve is also important to be able to plot a load-displacement curve or a moment-interaction diagram for confined member.

The location of $f_{\mathrm{t}}$ along the stress-strain curve is a function of the concrete strength, $f_{\mathrm{c}}^{\prime}$, which has a significant impact as the concrete starts to dilate and therefore bears against the jacket. Other important terms that would impact the value of $f_{\mathrm{t}}$ is the stress in the jacket at that point and the amount of jacket used, and the geometry of the cross-section. The stress in the jacket, $f_{\mathrm{jt}}$, is equal to $\varepsilon_{\mathrm{jt}} E_{\mathrm{j}}$. The portion of the jacket used and the cross-section of the column are represented by the volumetric ratio of FRP jacket, $\rho_{\mathrm{j}}$. No other apparent factors were shown to affect the location of $f_{\mathrm{t}}$.
Regression analysis is then performed between $\frac{f_{t}}{f_{c}^{\prime}}$ and $\frac{\rho_{\mathrm{j}} \mathrm{e}_{\mathrm{j}} E_{\mathrm{j}}}{f_{\mathrm{c}}^{\prime}}$. Figs. 9 and 10 show the results for such regression analysis for circular and rectangular columns, respectively.

The relationship between $\frac{f_{\mathrm{t}}}{f_{\mathrm{c}}^{\prime}}$ and $\left(\frac{\rho_{\mathrm{j}} E_{\mathrm{j}} \varepsilon_{\mathrm{j}}}{f_{\mathrm{c}}^{\mathrm{t}}}\right)^{\frac{5}{4}}$ may be approximated by a linear function. The following relation are obtained from regression analyses:

$\frac{f_{\mathrm{t}}}{f_{\mathrm{c}}^{\prime}}=\left\{\begin{array}{l}\text { For circular sections } \\ 1.0+3.0\left(\frac{\rho_{\mathrm{j}} E_{\mathrm{j}} \mathrm{c}_{\mathrm{j}}}{f_{\mathrm{c}}^{\prime}}\right)^{\frac{5}{4}} \\ \text { For rectangular sections } \\ 1.0+1.1350\left(\frac{\rho_{\mathrm{j}} E_{\mathrm{j}} \hat{\mathrm{j}}_{\mathrm{j}}}{f_{\mathrm{c}}^{\prime}}\right)^{\frac{5}{4}}\end{array}\right.$ 


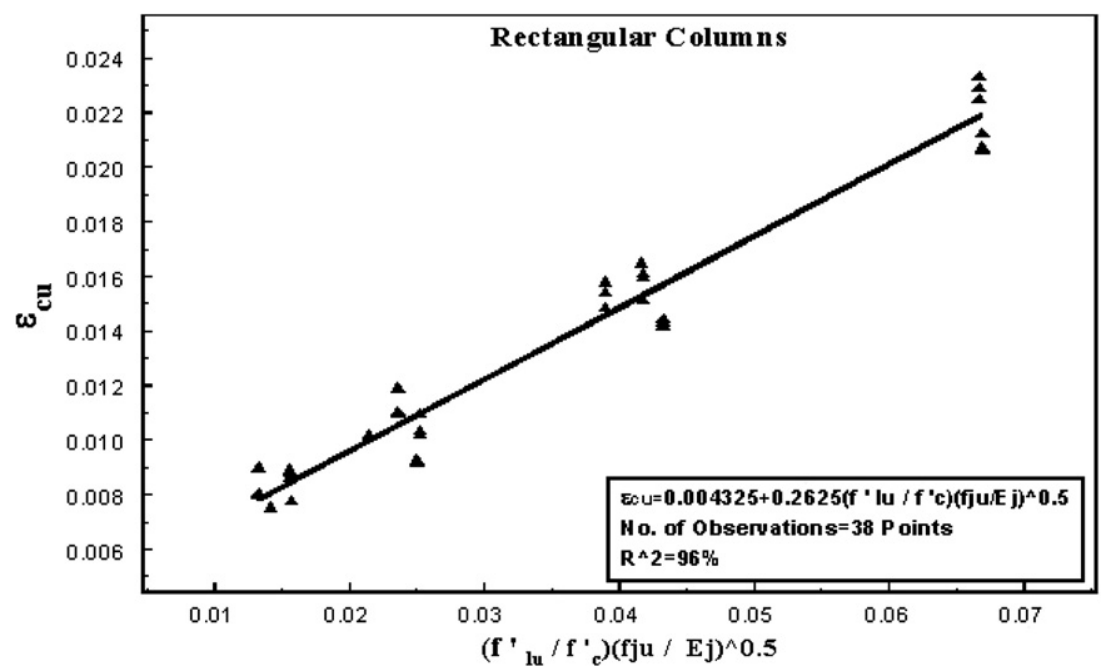

Fig. 8. Relationship for the ultimate strain for rectangular columns.

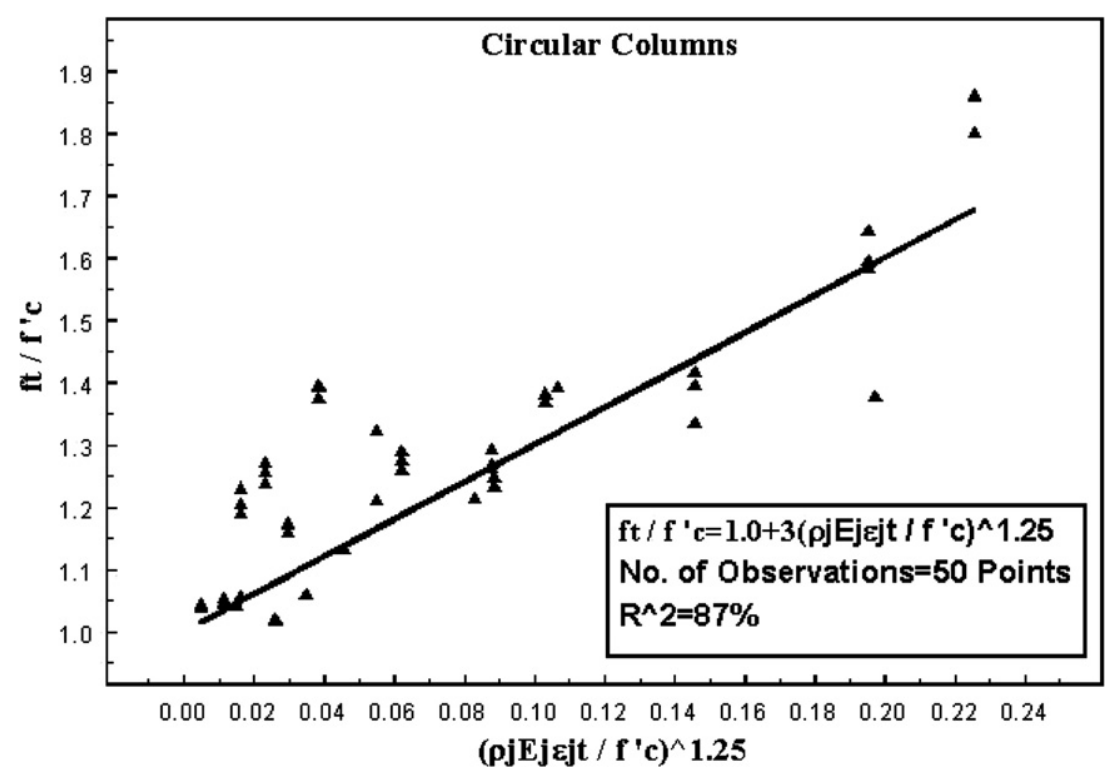

Fig. 9. Relationship for the axial stress $f_{\mathrm{t}}$ for circular columns.

The correlation coefficient for the circular sections is $87 \%$, using 50 data points, and is $90 \%$ using 38 data points for the rectangular sections.

\subsubsection{Axial strain, $\varepsilon_{\mathrm{t}}$}

The last parameter to be determined by regression analysis of the experimental data is the axial strain $\varepsilon_{t}$ corresponding to the axial stress $f_{\mathrm{t}}$.

This axial strain acts along the stress-strain curve located at the boundary between region 1 and region 2 . After deciding the regression terms for $f_{t}$, i.e. $\frac{\rho_{j} g_{j} E_{j}}{f_{c}^{\prime}}$, the use of the same term was attempted in the regression analysis of $\varepsilon_{\mathrm{t}}$. It was very obvious that $\frac{f_{\mathrm{t}}}{f_{\mathrm{c}}^{\prime}}$ and $\varepsilon_{\mathrm{t}}$ are in good relation with the hoop tension of the FRP jacket.

Figs. 11 and 12 show the confinement effectiveness factor $\left(\frac{\rho_{\mathrm{j}} E_{\mathrm{j}} \varepsilon_{\mathrm{j}}}{f_{\mathrm{c}}^{\prime}}\right)^{\frac{6}{7}}\left(\frac{f_{\mathrm{ju}}}{E_{\mathrm{j}}}\right)^{\frac{1}{2}}$ versus the axial strain, $\varepsilon_{\mathrm{t}}$.
The relationship between $\varepsilon_{\mathrm{t}}$ and $\left(\frac{\rho_{\mathrm{j}} E_{\mathrm{j}} \varepsilon_{\mathrm{j}}}{f_{\mathrm{c}}}\right)^{\frac{6}{7}}\left(\frac{f_{\mathrm{ju}}}{E_{\mathrm{j}}}\right)^{\frac{1}{2}}$ may be approximated by a linear function. The following relations are obtained from regression analyses:

$\varepsilon_{\mathrm{t}}=\left\{\begin{array}{l}\text { For circular sections } \\ 0.002748+0.1169\left(\frac{\rho_{\mathrm{j}} E_{\mathrm{j}} \varepsilon_{\mathrm{j}}}{f_{\mathrm{c}}^{\mathrm{c}}}\right)^{\frac{6}{7}}\left(\frac{f_{\mathrm{ju}}}{E_{\mathrm{j}}}\right)^{\frac{1}{2}} \\ \text { For rectangular sections } \\ 0.002+0.0775\left(\frac{\rho_{\mathrm{j}} E_{\mathrm{j}} \hat{j}_{\mathrm{j}}}{f_{\mathrm{c}}^{\prime}}\right)^{\frac{6}{7}}\left(\frac{f_{\mathrm{ju}}}{f_{\mathrm{c}}^{\prime}}\right)^{\frac{1}{2}}\end{array}\right.$

The correlation coefficient for the circular sections is $85 \%$, using 50 data points, and is $88 \%$ using 38 data points for the rectangular sections.

Tables 3 and 4 show the equations for the model parameters, with correlation coefficients and number of observations for circular and rectangular sections. 


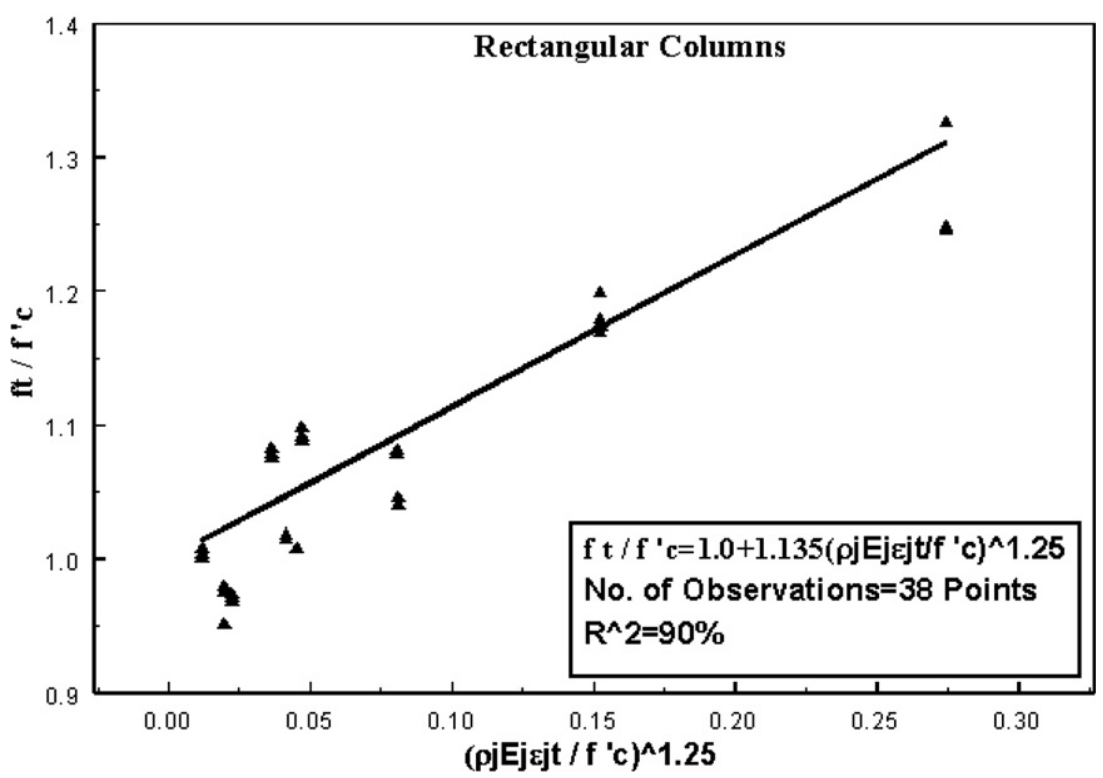

Fig. 10. Relationship for the axial stress $f_{\mathrm{t}}$ for rectangular columns.

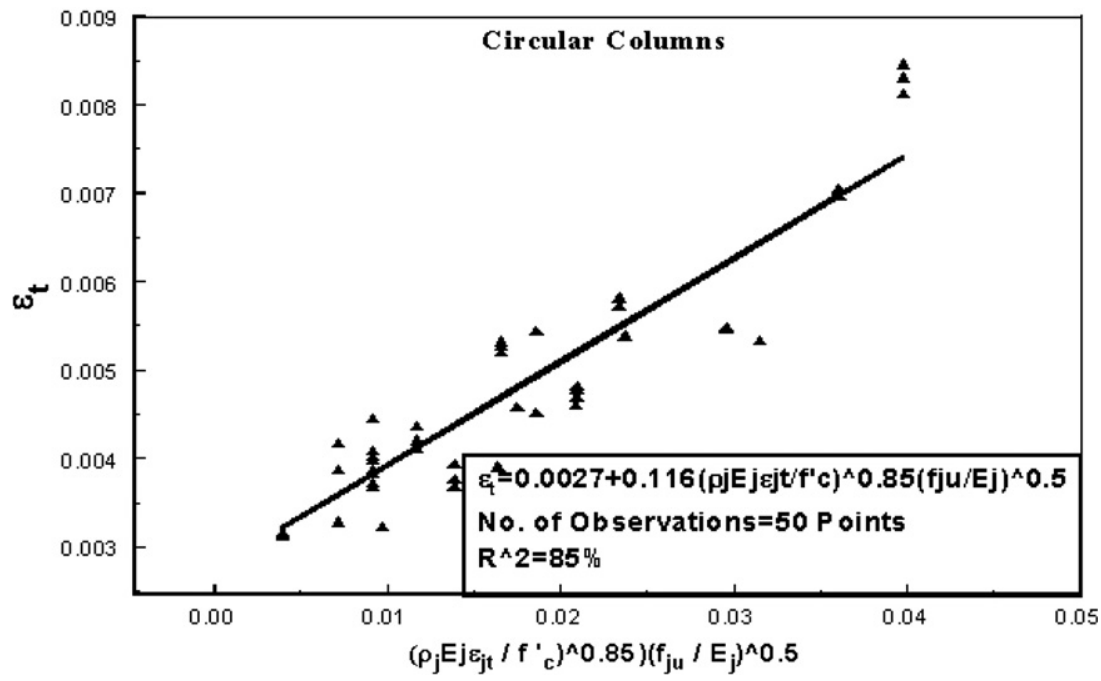

Fig. 11. Relationship for the axial stress $\varepsilon_{\mathrm{t}}$ for circular columns.

3.4.5. Slope of second branch, $E_{2}$

In this analysis, the portion of the stress-strain curve in region 2 was modeled as a straight line between the points $\left(\varepsilon_{\mathrm{t}}, f_{\mathrm{t}}\right)$ and $\left(f_{\mathrm{cu}}^{\prime}, \varepsilon_{\mathrm{cu}}\right)$ as follows:

$f_{\mathrm{c}}=f_{\mathrm{c}}^{\prime}+E_{2}\left(\varepsilon_{\mathrm{c}}-\varepsilon_{\mathrm{t}}\right)$

This is applicable to both ascending and descending cases, where $E_{2}$ is positive or negative, respectively.

With all of the confinement parameters known, the complete stress-strain behavior of the FRP-confined concrete members can now be described.

\section{General confinement model}

The parameters of the proposed confinement model that is applicable to circular and rectangular columns, are described below in their general form by the following equations:

$\frac{f_{\mathrm{cu}}^{\prime}}{f_{\mathrm{c}}^{\prime}}=\left[\alpha+\beta\left(\frac{f_{\mathrm{lu}}^{\prime}}{f_{\mathrm{c}}^{\prime}}\right)^{\gamma}\right]$

$\varepsilon_{\mathrm{cu}}=\left[\lambda+0.260\left(\frac{f_{\mathrm{lu}}^{\prime}}{f_{\mathrm{c}}^{\prime}}\right)\left(\frac{f_{\mathrm{ju}}}{E_{\mathrm{j}}}\right)^{\frac{1}{2}}\right]$

$\frac{f_{\mathrm{t}}}{f_{\mathrm{c}}^{\prime}}=\left[1.0+\eta\left(\frac{\rho_{\mathrm{j}} E_{\mathrm{j}} \varepsilon_{\mathrm{jt}}}{f_{\mathrm{c}}^{\prime}}\right)^{\frac{5}{4}}\right]$

$\varepsilon_{\mathrm{t}}=\left[\mu+\psi\left(\frac{\rho_{\mathrm{j}} E_{\mathrm{j}} \varepsilon_{\mathrm{jt}}}{f_{\mathrm{c}}^{\prime}}\right)^{\frac{6}{7}}\left(\frac{f_{\mathrm{ju}}}{E_{\mathrm{j}}}\right)^{\frac{1}{2}}\right]$

where $\alpha, \beta, \gamma, \eta, \mu$, and $\psi$ are shape factors that takes into effect the actual shape of the column, and are given in Table 5. 


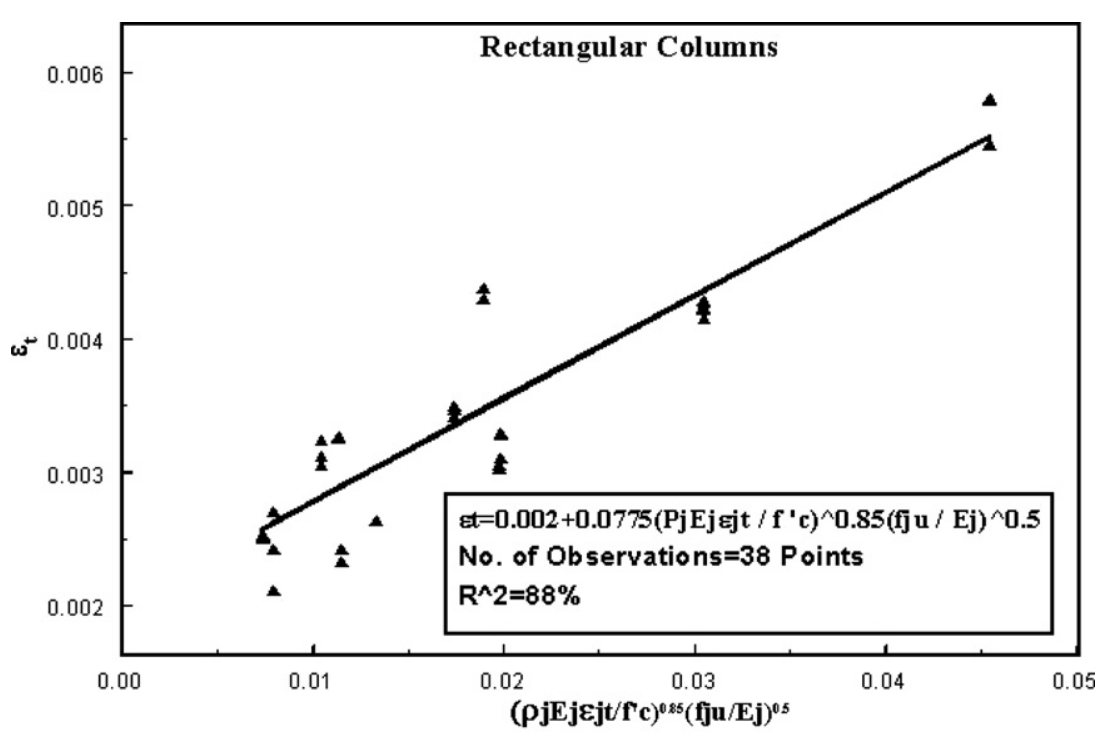

Fig. 12. Relationship for the axial stress $\varepsilon_{t}$ for rectangular columns.

Table 3

Equations and correlation coefficients for circular sections

\begin{tabular}{llll}
\hline $\begin{array}{l}\text { Model } \\
\text { parameter }\end{array}$ & Proposed equation & $\begin{array}{l}R^{2} \\
\%\end{array}$ & $\begin{array}{l}\text { No. of } \\
\text { observations }\end{array}$ \\
\hline$f_{\mathrm{cu}}^{\prime}$ & $1.0+2.25\left(\frac{f_{\mathrm{uu}}^{\prime}}{f_{\mathrm{c}}^{\prime}}\right)^{\frac{5}{4}}$ & 93 & 63 \\
$f_{\mathrm{c}}^{\prime}$ & $0.003368+0.2590\left(\frac{f_{\mathrm{lu}}^{\prime}}{f_{\mathrm{c}}^{\prime}}\right)\left(\frac{f_{\mathrm{ju}}}{E_{\mathrm{j}}}\right)^{\frac{1}{2}}$ & 94 & 63 \\
$\varepsilon_{\mathrm{cu}}$ & 87 & 50 \\
$f_{\mathrm{t}}$ & $1.0+3.0\left(\frac{\rho_{\mathrm{j}} E_{\mathrm{j}} \varepsilon_{\mathrm{j}}}{f_{\mathrm{c}}^{\prime}}\right)^{\frac{5}{4}}$ & 85 & 50 \\
\hline$f_{\mathrm{c}}^{\prime}$ & $0.002748+0.1169\left(\frac{\rho_{\mathrm{j}} E_{j_{\mathrm{j}}} \delta_{\mathrm{c}}^{\prime}}{f_{\mathrm{c}}^{\prime}}\right)^{\frac{6}{7}}\left(\frac{f_{\mathrm{ju}}}{E_{\mathrm{j}}}\right)^{\frac{1}{2}}$ & 85 & \\
\hline
\end{tabular}

Table 4

Equations and correlation coefficients for rectangular sections

\begin{tabular}{llll}
\hline $\begin{array}{l}\text { Model } \\
\text { parameter }\end{array}$ & Proposed equation & $\begin{array}{l}R^{2} \\
\%\end{array}$ & $\begin{array}{l}\text { No. of } \\
\text { observations }\end{array}$ \\
\hline$f_{\mathrm{cu}}^{\prime}$ & $0.5+1.225\left(\frac{f_{\mathrm{lu}}^{\prime}}{f_{\mathrm{c}}^{\prime}}\right)^{\frac{3}{5}}$ & 94 & 38 \\
$f_{\mathrm{c}}^{\prime}$ & $0.004325+0.2625\left(\frac{f_{\mathrm{lu}}^{\prime}}{f_{\mathrm{c}}^{\prime}}\right)\left(\frac{f_{\mathrm{ju}}}{f_{\mathrm{c}}^{\prime}}\right)^{\frac{1}{2}}$ & 96 & 38 \\
$\varepsilon_{\mathrm{cu}}$ & $1.0+1.1350\left(\frac{\rho_{\mathrm{j}} E_{\mathrm{j}} \varepsilon_{\mathrm{j}}}{f_{\mathrm{c}}^{\prime}}\right)^{\frac{5}{4}}$ & 90 & 38 \\
$f_{\mathrm{t}}$ & $0.002+0.0775\left(\frac{\rho_{\mathrm{j}} E_{\mathrm{j}} \varepsilon_{\mathrm{jt}}}{f_{\mathrm{c}}^{\prime}}\right)^{\frac{6}{7}}\left(\frac{f_{\mathrm{ju}}}{f_{\mathrm{c}}^{\prime}}\right)^{\frac{1}{2}}$ & 88 & 38 \\
\hline$\varepsilon_{\mathrm{t}}^{\prime \prime}$ &
\end{tabular}

Table 5

Proposed general model shape factors

\begin{tabular}{llllllll}
\hline & $\alpha$ & $\beta$ & $\gamma$ & $\lambda$ & $\eta$ & $\mu$ & $\psi$ \\
\hline Circular & 1 & 2.25 & 1.25 & 0.00337 & 3 & 0.00274 & 0.117 \\
Rectangular & 0.5 & 1.225 & 0.6 & 0.00433 & 1.135 & 0.0020 & 0.078 \\
\hline
\end{tabular}

\section{Performance analysis of proposed model}

\subsection{Model parameters}

The four parameters of the proposed model $\left(f_{\mathrm{cu}}^{\prime}\right.$, $\left.\varepsilon_{\mathrm{cu}}, f_{\mathrm{t}}, \varepsilon_{\mathrm{t}}\right)$ were analyzed, experimental versus theoretical values, to determine their correlation. The comparison was performed using the normalized effective lateral confining stress at ultimate conditions, $f_{\text {lu }}^{\prime} / f_{\mathrm{c}}^{\prime}$. The normalized factor represents the amount of confinement provided to the columns. A good correlation between the experimental and theoretical values was observed. The majority of the points fell between 0.8 and 1.2 along the $y$-axis indicating good predictions.

\subsection{The proposed model versus experimental results}

Fig. 13 shows the experimental stress-strain curves for the circular columns confined with carbon/epoxy jacket compared with the theoretical stress-strain curve from the proposed model. As shown, excellent correlation is achieved in predicting the actual performance of the large-scale circular columns with FRP jackets.

\subsection{Comparison between proposed versus existing models}

The performance of the proposed model versus other models available in the literature is compared to the experimental data. In order to show the effectiveness of the proposed model, the stress-strain relations predicted by previous models were computed for selected test specimens and compared with the experimental results. The comparison is performed based on the entire stress-strain curve as well as for the actual values of the ultimate strength of FRP-confined concrete, $f_{\mathrm{cu}}^{\prime}$, and the ultimate concrete compressive strain, $\varepsilon_{\mathrm{cu}}$.

\subsubsection{Circular specimens}

A total of five existing concrete confinement models were studied and compared to the proposed model. Those models are in $[9,11,17,19,27]$. 


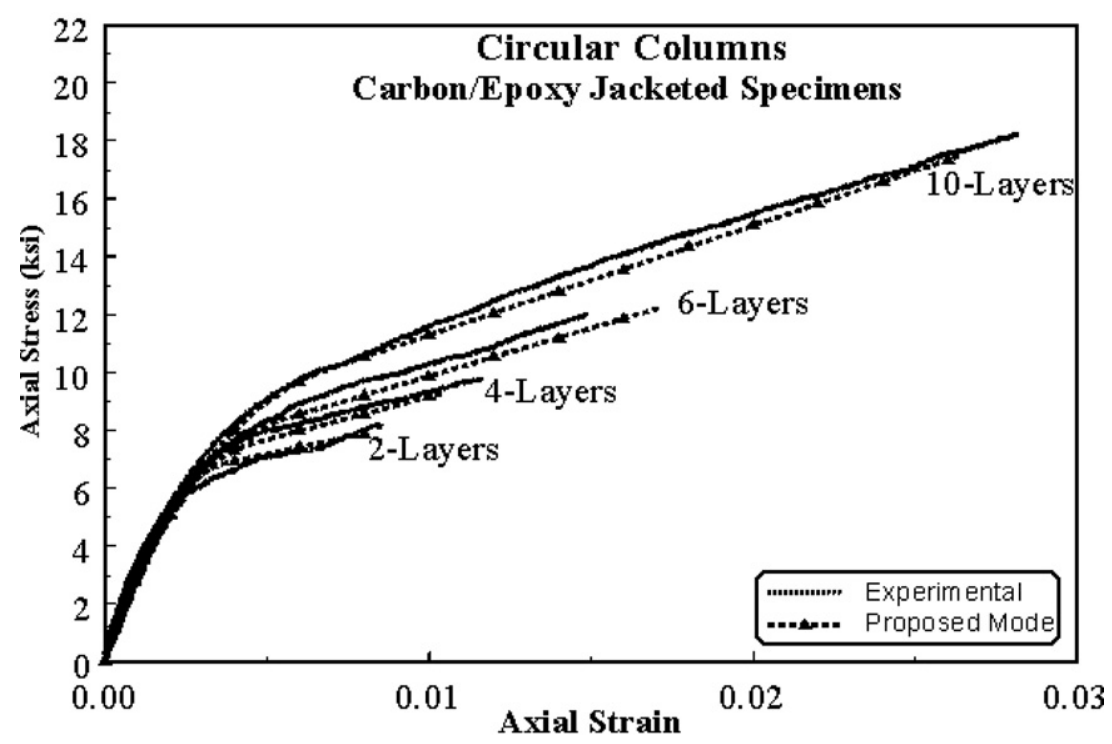

Fig. 13. Proposed model versus experimental data for circular columns.

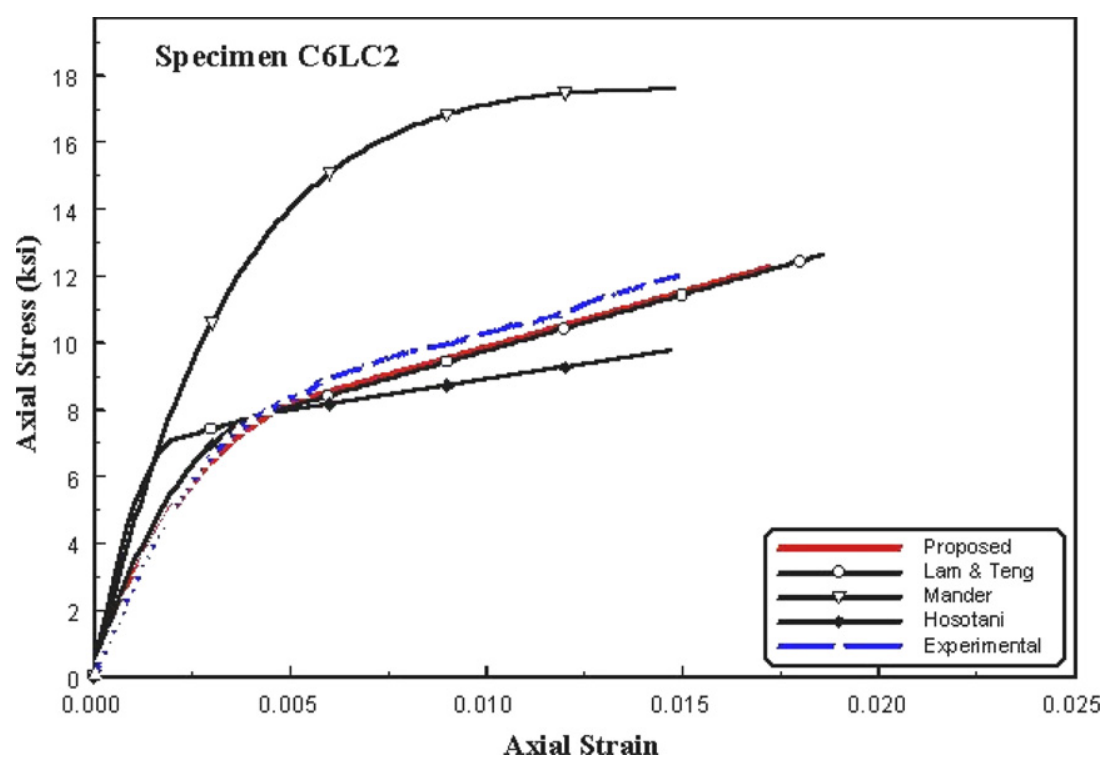

Fig. 14. Comparison of confinement models to stress-strain curve of C6LC2.

Fig. 14 compares the theoretical stress-strain curves generated from the five published models with the experimental curve, for selected specimen, produced from the study. As shown in this figure, Mander's model $[18,19]$ seems to always overestimate the confined concrete stress, $f_{\mathrm{cu}}^{\prime}$, where as its ultimate confined concrete strain, $\varepsilon_{\mathrm{cu}}$, prediction varies depending upon the confinement ratio used.

It should be noted that the theoretical curves of both the Hoppel [9] and Samaan [27] models were omitted from the presented stress-strain curves. The reason behind this omission is that these two models, in certain cases, predicted curves that were not close to the experimental values. These models, however, are shown on the bar charts of the specimens for comparison. Model comparisons are presented in Figs. 14 and 15.
Fig. 14 indicates that the proposed model best predicts the experimental results as compared to other models.

\subsubsection{Rectangular specimens}

Due to the limited available confinement models that are applicable to square and rectangular columns, only two existing concrete confinement models were evaluated and compared to the proposed model. These models are (i) Hosotani's model [11], and (ii) Mander's model [18,19].

Figs. 16 and 17 compare the entire theoretical stressstrain curves from the two published models and compare these two models with the experimental curves, for selected specimens, produced from the study. Similar to circular columns, Mander's model appears to always overestimate the confined concrete stress, $f_{\mathrm{cu}}^{\prime}$. In addition, the estimation 


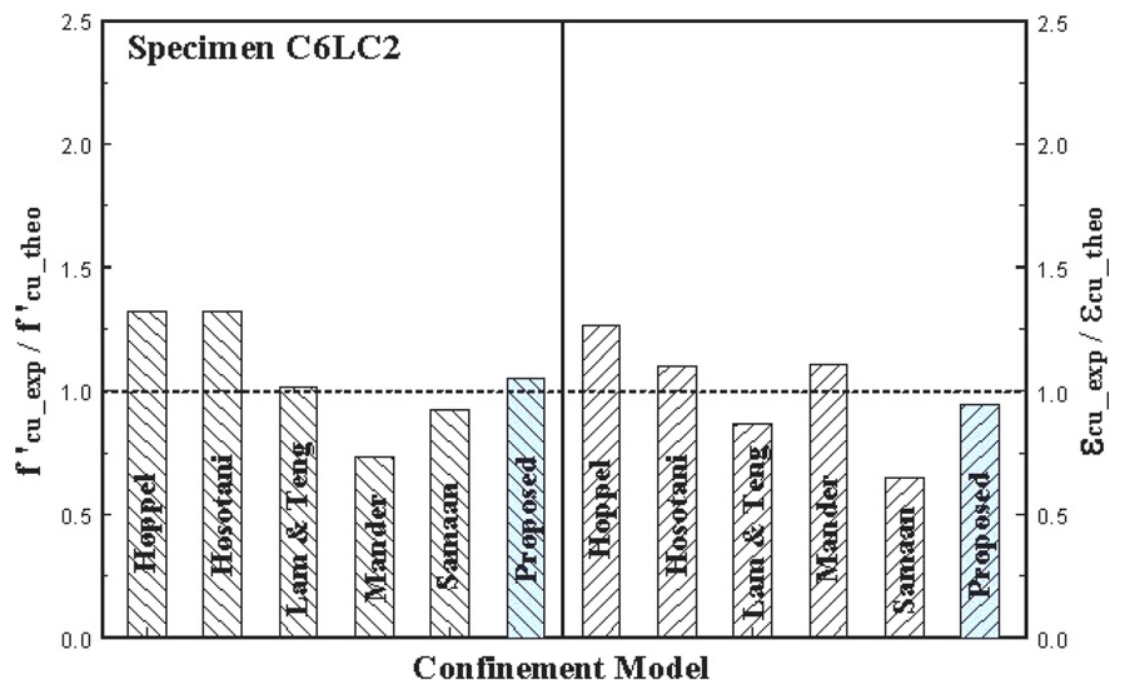

Fig. 15. Comparison of confinement models to C6LC2 results.

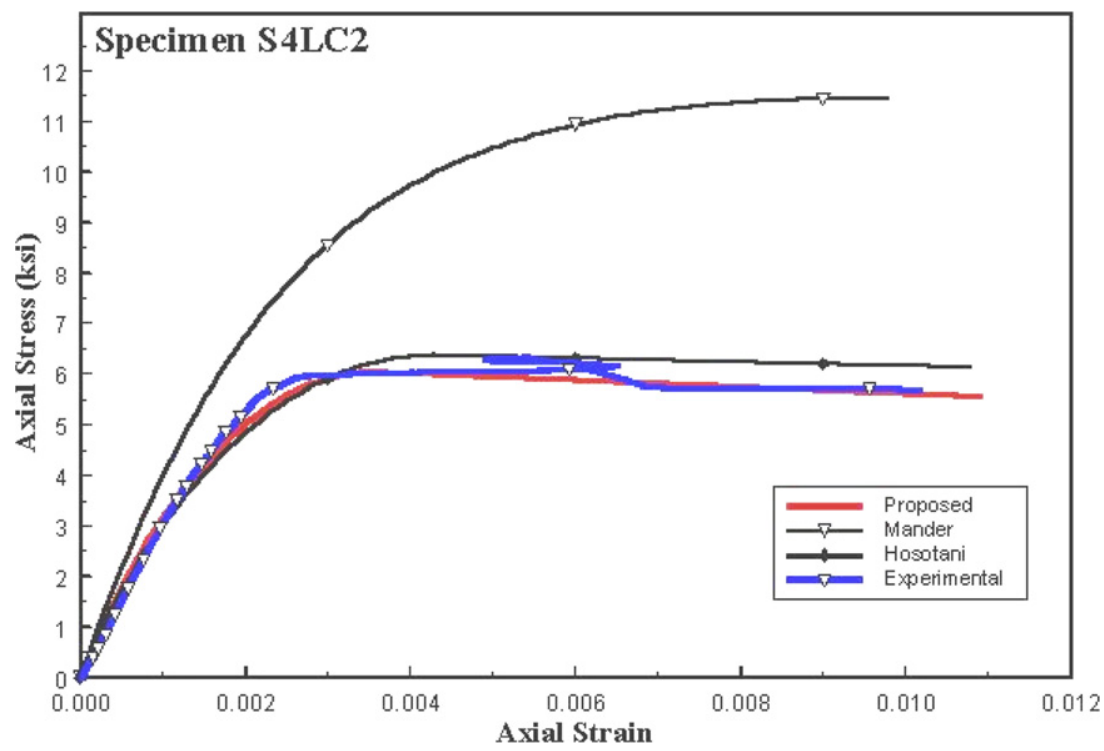

Fig. 16. Comparison of confinement models to stress-strain curve of S4LC2.

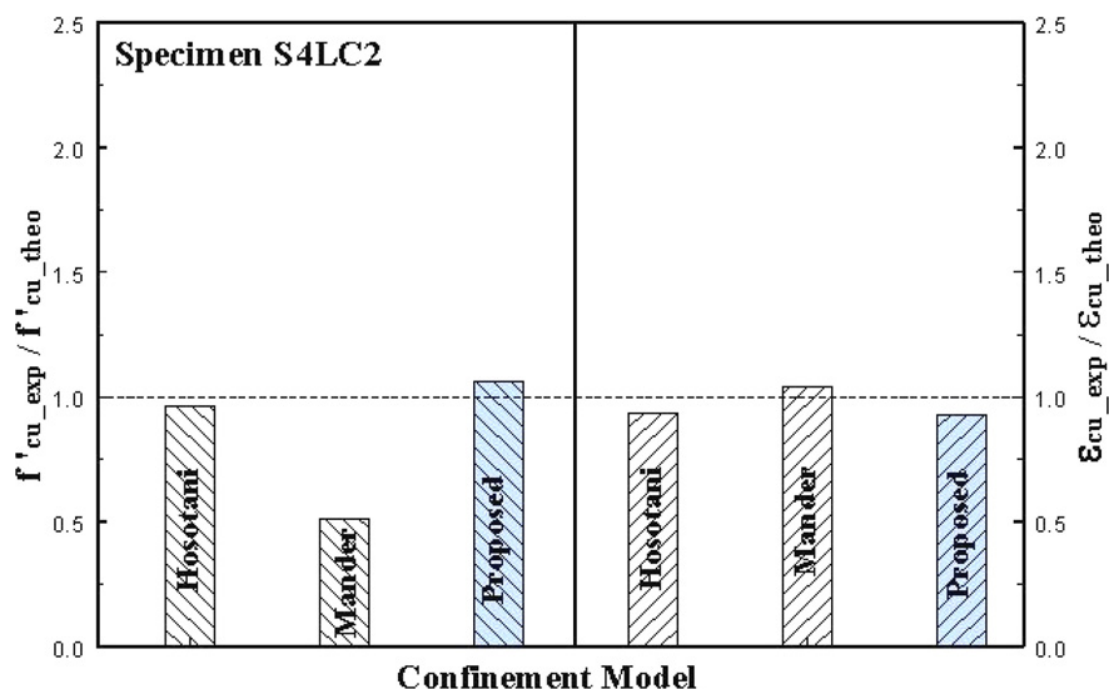

Fig. 17. Comparison of confinement models to S4LC2 results. 
of the ultimate confined concrete ultimate strain, $\varepsilon_{\mathrm{cu}}$, using this model varies depending on the confinement ratio of the specimen under consideration.

\section{Conclusions}

A general unified FRP-confined concrete model is proposed. The proposed model was verified using both the experimental results generated from this study as well as other previously published data. The results of this study indicated that this model can effectively predict the behavior of both circular as well as rectangular columns. The majority of the experimental data used in developing this semi-empirical model were generated from large-scale specimens under axial load.

Based on the results of the analytical procedures developed in this study, the following conclusions are made:

1. The stress-strain curve for concrete confined by FRP composites behaves bilinearly. The first portion of the stress-strain curve traces that of unconfined concrete until the jacket start to get activated. At this point, the curve became either ascend or descend, depending on the geometry of the cross-section and the confinement ratio provided.

2. Mander's model $[18,19]$, was found, in most cases, to overestimate the concrete ultimate confined strength, regardless to the confinement ratio. On the other hand, results indicated that the variation of the predicted ultimate strain using Mander's model depends largely on the confinement ratio.

3. In most of the cases, Samaan's model [27] overestimated the ultimate concrete strain.

4. It was observed that although the Lam and Teng model [17] predicted the ascending portion of the stress-strain curve of confined concrete for certain confinement ratios, it did not do well in tracing the initial portion of the stress-strain curve. Also, the concrete modulus of elasticity recommended by the Lam and Teng model does not correlate well with the experimental results of this study and others.

5. Some of the confinement models evaluated in this study were effective within certain range of confinement ratios, and not within others. The proposed model was successful in covering a wide range of confinement ratios which was possible to generate by testing large-scale columns as opposed to the majority of the published tests that were conducted on standard $152 \mathrm{~mm} \times 305 \mathrm{~mm}$ (6 in. $\times$ 12 in.) standard cylinders. As a result, a great correlation is achieved for all tested specimens.

6. The proposed unified confinement model generated from this study proved to be a very effective prediction tool as compared to experimental data, whereas other models either overestimated or under estimated both the ultimate stress and ultimate strain values. The proposed model was found also very effective in predicting the entire stress-strain diagram of the tested specimens.

\section{Acknowledgements}

The FRP materials used in the study was provided by Edge Structural Composites Inc. The authors would like to acknowledge the contributions of Mr. J. Kiech, Mr. J. Vargas, Mr. D. Mikhael, and Mr. T. Tietz to the experimental verification program.

\section{References}

[1] ACI 440.2R-02. Guide for the design and construction of externally bonded FRP systems for strengthening concrete structures. American Concrete Institute, Farmington Hills, Michigan, 2003.

[2] De Lorenzis L. A comparative study of models on confinement of concrete cylinders with FRP composites. Division of Building Technology, Chalmers University of Technology, Work No. 46, Publication: 01:04.

[3] Demers M, Hebert D, Labossiere P, Neale KW. The strengthening of structural concrete with aramid woven fiber/epoxy resin composite. In: Proceedings of advanced composite materials in bridges and structures II, Montreal, August 1995. p. 435-42.

[4] Fam A, Flisak B, Rizkalla S. Experimental and analytical modeling of concrete-filled fiber-reinforced polymer tubes subjected to combined bending and axial loads. ACI Struct J 2003;100(4):499-509.

[5] Harries KA, Kestner J, Pessiki S, Sause R, Ricles J. Axial behavior of reinforced concrete columns retrofit with FRP jackets. Second international conference on composites in infrastructure ICCI'98, Tucson, Arizona, USA, 5-7 January 1998.

[6] Harmon T, Slattery K. Advanced composite confinement of concrete. Advanced composite materials in bridges and structures. CSCE; 1992, p. 299-306.

[7] Haroun MA, Feng MQ, Elsanadedy HM, Mosallam AS. Composite jackets for the seismic retrofit and repair of bridge columns. In: Proceedings of the seventh US national conference on earthquake engineering, Boston, USA, 2002.

[8] Haroun MA, Feng MQ, Youssef MN, Mosallam AS. Seismic retrofit of reinforced concrete columns using FRP composite laminates. In: Proceedings of second conference on seismic repair and rehabilitation of structures (SRRS2), Fullerton, CA, USA, March 21-22, 2000.

[9] Hoppel CR, Bogetti TA, Gillespie Jr JW, Howie I, Karbhari VM. Analysis of a concrete cylinder with a composite hoop wrap. Proceedings of the ASCE materials engineering conference. New York, NY: ASCE; 1994, p. 191-8.

[10] Hoshikuma J, Kawashima K, Nagaya K, Taylor AW. Stress-strain model for confined reinforced concrete in bridge piers. J Struct Eng 1997.

[11] Hosotani M, Kawashima K, Hoshikuma Jun-ichi. A stress-strain model for concrete cylinders confined by carbon fiber sheets. Report no. TIT/EERG 98-2, Tokyo Institute of Technology, Tokyo, Japan, 1998. 55 pp [in Japanese].

[12] Hosotani M, Kawashima K, Hoshikuma Jun-ichi. A stress-strain model for concrete cylinders confined by carbon fiber sheets. J Concr Eng JSCE 1998;39(592):37-52 [in Japanese].

[13] Karabinis AI, Rousakis TC. Carbon FRP confined concrete elements under axial load. Proc FRP Compos Civil Eng 2001;1:309-16.

[14] Kono S, Inazumi M, Kaku T. Evaluation of confining effects of CFRP sheets on reinforced concrete members. In: Proceedings of the second international conference on composites in infrastructure ICCI'98, Tucson, Arizona, 5-7 January 1998. p. 343-55.

[15] Labossiere P, Neale K, Demers M, Picher F. Repair of reinforced concrete columns with advanced composite materials confinement. Advanced composite materials in bridges and structures. CSCE; 1992.

[16] Lam L, Teng JG. Strength models for fiber-reinforced plasticconfined concrete. J Struct Eng ASCE 2002(May):612-23.

[17] Lam L, Teng JG. A new stress-strain model for FRP-confined concrete. Proc FRP Compos Civil Eng 2001;1:283-92. 
[18] Mander JB, Priestley MN, Park R. Theoretical stress-strain model for confined concrete. J Struct Div ASCE 1988;114(8):1804-26.

[19] Mander JB, Priestley MN, Park R. Observed stress-strain behavior of confined concrete. J Struct Div ASCE 1988;114(8):1827-49.

[20] Mirmiran A, Shahawy M. Model of concrete confined by fiber composites. J Struct Div ASCE 1988;123(5).

[21] Picher F, Rochette P. Confinement of concrete cylinders with CFRP. In: Proceedings of first international conference on composite infrastructures, Tucson, Arizona, 1996. p. 829-41.

[22] Priestley MJN, Fyfe E, Seible F. Column retrofit using fiberglass/ epoxy jackets. In: Proceedings of the first annual seismic research workshop, California Department of Transportation, Division of Structures, December 3-4, 1991. p. 217-24.

[23] Restrepo JI, DeVino B, Enhancement of the axial load carrying capacity of reinforced concrete columns by means of fiberglass-epoxy jackets. In: Proceedings of advanced composite materials in bridges and structures II, Montreal, August 1995. p. 547-53.

[24] Richart FE, Brantzaeg A, Brown RL. A study of the failure of concrete under combined compressive stresses. Bulletin No. 185, Engineering Experiment Station, University of Illinois, Urbana, IL, 1928. $104 \mathrm{p}$.

[25] Rousakis T. Experimental investigation of concrete cylinders confined by carbon FRP sheets, under monotonic and cyclic axial compressive load. Research report, Chalmers University of Technology, Gteborg, Sweden.

[26] Saafi M, Toutanji HA, Li Z. Behavior of concrete columns confined with fiber reinforced polymer tubes. ACI Mater J 1999;96(4):500-9.

[27] Samaan M, Mirmiran A, Shahawy Mohsen. Model of concrete confined by fiber composites. J Struct Eng ASCE 1998;124(9): $1025-31$.

[28] Seible F, Hegemier GA, Priestley MJN, Innamorato D, Ho F. Carbon fiber jacket retrofit test of rectangular flexural column with lap spliced reinforcement. Advanced Composites Technology Transfer Consortium Report No. ACTT-95/02, UCSD, March 1995. 53 p.

[29] Spoelstra MR, Monti G. FRP-confined concrete model. J Compos Construct ASCE 1999;3(3):143-50.

[30] Toutanji H. Stress-strain characteristics of concrete columns externally confined with advanced fiber composite sheets. ACI Mater J 1999;96(3):397-404.

[31] Xiao Y. Compression tests of concrete cylinders confined by carbon fiber composite jacket. USC Structural Engineering Research Report No. USC-SERP 98/06, September 1998.

[32] Xiao Y, Wu H. Compressive behavior of concrete cylinders confined by carbon fiber composite jackets. Am Soc Civil Eng, ASCE J Mater Civil Eng 2000;12(2):139-46.

[33] Xiao Y, Wu H. Compressive behavior of concrete confined by various types of FRP composite jackets. J Reinf Plast Compos 2003;22(13):1187-202.

[34] Youssef MN, Haroun MA, Feng MQ, Mosallam AS. Experimental study on RC bridge columns retrofitted using fiber composite materials. In: Proceedings of the 45th international SAMPE symposium, May 21-25, 2000.

[35] Youssef MN, Mosallam AS, Feng MQ. Experimental investigation on FRP-confined concrete columns. In: Proceedings of the ninth international conference on composites engineering, ICCE/9, San Diego, USA, July 1-6, 2002.

[36] Youssef MN. Stress-strain model for concrete confined by FRP composites. Ph.D. Dissertation, University of California, Irvine, March 2003.

[37] Youssef MN, Mosallam AS, Feng MQ. Experimental investigation on large-scale FRP-confined axial members. In: Proceedings of the international conference on civil engineering infrastructure systems (CEIS 2006), American University of Beirut (AUB), Beirut-Lebanon, June 12-14, 2006. 